\title{
A Spaghetto a Day Keeps Allergies Away
}

\author{
ROBERT M. GENTA, MD
}

Even in these times of political correctness, when references to ethnic or national stereotypes are strongly discouraged and often severely rebuked, some words have maintained an indelible association with a people or a country. Negative connotations may have been diluted, globalization may have made the specific ethnic characterizations obsolete, but the subconscious associations that would emerge on the psychoanalyst's coach remain firmly anchored to our collective subconscious. Marco Polo and Ibn Battuta may have been responsible for importing from China a dough in the form of thin strings that eventually took its name from the diminutive of the Italian word for string ("spago"; hence "spaghetto" and, finally, the commonly used plural, "spaghetti"). Bowing to the Classics, the British Pasta Association prefers to attribute the discovery to Volcano, the Greek god who allegedly forged a device to give pasta its filiform shape. Americans consume more spaghetti per capita that any other nation in the world, and the Old Spaghetti Factory is a successful Oregon-based all-American restaurant chain; Swiss children have admitted in a recent survey to prefer spaghetti to Rösti or fondue (1); and a plate of spaghetti alla carbonara cooked to perfection can be found as easily in Kyoto as in Copacabana.

Yet, despite the globalization of spaghetti, the primary cultural link of these fragile pasta sticks remains Italy. Generation-X Americans growing up on frozen pizza may experience some difficulties when asked to identify their most beloved symbol of the American home: Mom is still solidly represented, but pizza may be slowly replacing apple pie.

In the 70s, when I had a brief medical experience in the northern Italian region of Piedmont, fast food was

\footnotetext{
Manuscript received May 25, 2003; accepted August 21, 2003.

From the Department of Pathology, University Hospitals, Geneva, Switzerland.

Prepared as an invited editorial response to Nucera et al., "New Protocol for Oral Desensitization to Wheat Allergy in a Single Case," the preceding Case Report.

Address for reprint requests: Robert M. Genta, MD, Division de Pathologie Clinique, Rue Micheli-du-Crest 24, CH-1211 Genève 14, Switzerland; Robert.Genta@medecine.unige.ch.
}

an alien concept, and the few who understood the term "hamburger" visualized (not without some lingering postbellum unease) a person from Hamburg, Germany. Today, Big Macs and Taco Bellgrandes have become part of the normal diet of an increasingly plump generation of southern Italian youngsters. Yet mothers in both regions, then and now, would complain to their pediatricians with colorful gestures and dramatic prose that their children do not eat enough spaghetti. Not only is this alimentary aberration unconsciously equivalent to a mild form of sociopathy, but it causes grave concerns about growth and development. Innumerable Italian proverbs and expressions link spaghetti to health and strength. An Italian child who becomes ill from eating spaghetti risks a life of mockery and could become an outcast deprived of a convivial future.

The team of allergologists and gastroenterologists led by Professor Patriarca at the Catholic University in Rome met such a child, a 7-year old girl for whom just sitting at her Roman dinner table and rolling up a few spaghetti on her fork immediately precipitated abdominal pain, diarrhea, asthma, and facial angioedema. Wheat, not gluten, was found to be responsible, and a desensitization protocol was devised. Over a period of 215 days, the little girl's only medication consisted of adding 1 spaghetto a day to the initial single-spaghetto dose, which corresponds to $1.2 \mathrm{~g}$ of pasta, up to 41 spaghetti three times a day (147 $\mathrm{g}$ of pasta). At the end of this unusual protocol, the child-who never experienced allergic symptoms-was given $50 \mathrm{~g}$ of bread, which she ingested with great pleasure and no untoward consequences. She could join the ranks of her spaghetti-eating compatriots.

Patriarca's team had previously developed original protocols for desensitization in food allergies $(1,2)$, and this case is another example of the innovative approaches they take to relieving patients from potentially crippling food sensitivities.

Since the authors admit that the clinical improvement was not paralleled by a normalization of the laboratory values (presumably the specific IgE elevation), the possibility that the clinical tolerance is precarious must be 
considered. There are examples of individuals becoming temporarily tolerant to certain insect venoms, who later in life succumb to a single bite capable of unleashing an anaphylactic reaction $(3,4)$. Thus, the authors' recommendation that the patient remain on an indefinite maintenance therapy consisting of daily pasta dishes may be the key to maintaining tolerance. One only hopes that their little patient does not take the recommendation overenthusiastically, and that the 3,142,625 spaghetti she will have to eat over her expected lifetime of 77 years will not have an adverse effect on her figure. After all, the perils of pasta go well beyond allergic reactions $(5,6) \ldots$

\section{REFERENCES}

1. Diehl JM: Food preferences of 10- to 14-year-old boys and girls. Schweiz Med Wochenschr 129:151-161, 1999

2. Patriarca G, Nucera E, Roncallo C, Pollastrini E, Bartolozzi F, De Pasquale T, Buonomo A, Gasbarrini G, Di Campli C, Schiavino D: Oral desensitizing treatment in food allergy: clinical and immunological results. Aliment Pharmacol Ther 17:459-465, 2003

3. Golden DB. Fatal insect allergy after discontinuation of venom immunotherapy. J Allergy Clin Immunol 107:925-926, 2001

4. Light WC: Insect sting fatality 9 years after venom treatment (venom allergy, fatality). J Allergy Clin Immunol 107:925, 2001

5. Bacci M, Porena M: Masturbation injury resulting from intraurethral introduction of spaghetti. Am J Forensic Med Pathol 7:254-255, 1986

6. Underwood A: The perils of pasta. Newsweek 134:89-90, 1999 